\title{
Never Enough Hours in the Day: Employed mothers’ perceptions of time pressure
}

Judy Rose

Author: Dr Judy Rose - corresponding author - j.rose@griffith.edu.au

Griffith Institute for Educational Research (GIER), Mt Gravatt Campus, Griffith University, QLD

\begin{abstract}
Finding sufficient time to meet work and family commitments poses immense challenges for employed mothers in 21st Century contemporary life. Understanding how employed women with children manage their finite time resources requires deeper investigation of how time pressures accrue across work and home contexts. This study draws on data from in-depth interviews with 18 working mothers from diverse occupations (professional, sales, service, clerical, technical and trades) and across a range of employment hours (full and part-time). The findings from this study show that employed mothers endure high levels of time pressure related to time poverty (insufficient time for necessary or discretionary activities), time intensity (multi-tasking and merging work and home boundaries), and time density (familial emotion and organisation work). When women use strategies to increase time efficiency, it does not necessarily reduce their perceptions of time pressure. Juggling multiple tasks simultaneously distorts women's temporal experiences and diminishes the quality of time. Workplaces and policy-makers need to find better ways to encourage employed fathers to share the responsibility for home and familyrelated care and organisational work. Such measures may reduce the time stress and time inequity women endure, particularly in the time management control centre of the home.
\end{abstract}

Key Words: time pressure, time poverty, employed mothers, work-family policy, qualitative

\section{Author Bio}

Judy Rose is a sociologist and the convenor of the Families \& Relationships thematic group for The Australian Sociological Association (TASA). Her research interests include gender inequalities in family and work; and child poverty and disadvantage in education. 


\section{Introduction}

Time use surveys consistently find employed mothers to be among the highest time pressured groups in society (ABS, 2008; Baxter, 2009; Skinner et al., 2012). The 2010 Australian Work \& Life Index (AWALI) study found 69.4\% of employed mothers felt 'often or almost always rushed or pressed for time’, compared with 58\% of employed fathers (Pocock, Skinner \& Pisaniello., 2010). This 11.4 percentage point difference is largely due to the disproportionate amount of time women spend relative to men on housework and child care tasks, with women experiencing higher time pressure at home than men (Craig, 2006; Baxter, Hewitt \& Haynes, 2008; Rose, Hewitt \& Baxter, 2013). Trends in delayed childbearing and ageing of the population in Western countries such as Australia mean that women are often caring for dependent children and aged relatives simultaneously, further adding to an overall time burden (Duncan \& Pettigrew, 2012). The countervailing time pressures working mothers face in establishing careers while rearing their children contributes to a 'time squeeze bottleneck' (Craig, 2007: 135). A growing body of research is beginning to recognise that living a time balanced life promotes health and wellbeing, while time pressure negatively affects physical and mental health (Strazdins et al., 2004; Pocock et al., 2010; Baxter, 2009).

A less explored source of time pressure for women is the responsibility for the organisation of time resources across the work-family nexus (Connell, 2005; Maher, Lindsay \& Franzway, 2008). The time demands associated with familial scheduling usually occur in the home domain, and therefore it is an area of time inequality that few policies have directly addressed (Jacobs \& Gerson, 2004). Further, the qualitative experience of juggling multiple time demands across the temporalities of post-modern family life, arguably require closer investigation. As Craig et al. (2008:2) have argued, 'While time-demand and time-pressure are at the nub of the difficulty in managing work and family, very little of the research into this issue has studied it directly from this perspective'.

Some of the broader work-family time-balance policies introduced in Australia over the past two decades include the Child Care Benefit (2000) for approved child care, the right to request flexible work hours (2008) and the government Paid Parental Leave (2011) and Dad and Partner Pay (2013) schemes (Australian Government, Department of Human Services, 2016). Despite these promising innovations, the prevailing social policy in Australia has remained 
broadly supportive of gender specialisation in the provision of care, while at the same time endorsing polices that increase women’s workforce participation (O’Connor, Orloff \& Shaver, 1999; Hill, 2007).

This paper proposes to look at the detailed narratives of women's lives to investigate how they perceive time and develop strategies for managing it. This type of in-depth exploration has not been conducted in previous Australian time use research (Craig et al., 2008). This study proposes that perceptions of time and strategies of time management are linked, and that some strategies may increase rather than reduce time pressure. The structure of this paper is as follows: (1) a brief background on the sociology of time in work and family contexts followed by (2) an overview of the study design and methods. The analysis of findings is divided into two main sections beginning with (3) a description of the strategies women use to manage time, before (4) examining the effect these strategies have on women's temporal perceptions, including time poverty and time pressure. The main question driving this research is: How do employed mothers perceive and manage time pressure in their daily lives?

\section{It's about time}

It is pertinent to examine briefly how time has regulated patterns of work and family life from modern (industrial) to post-modern (post-industrial) times. In the industrial era, time was conceptualised in a linear way, as a commodity that was measured by the clock. The boundary between market (paid) and non-market (unpaid) work came into place at the time of industrialisation (Reskin \& Padavic, 2002). When the home domain became separated from industrialised workplaces, unpaid domestic time use became obfuscated. This invisibility of unpaid work remains problematic, even with women's increased workforce participation, as it tends to hide potential sources of time pressure. Recent research suggests the home continues to be a key site for organising and managing familial time resources, and a site that is a time management command centre for women (Maher et al., 2008; Rose et al., 2015).

In the current post-industrial, post-modern workplaces, time has been reconceptualised to become more fluid and managed to a greater degree by individuals across a variety of spaces and time zones (Brannen, 2005; Westenholz, 2006). Yet, research has found flexible work practices have only a weak relationship with the amount of time parents spend with their children (Baxter 
2011). As Craig's (2007) study found, employed mothers find alternative ways to maximise their time with children, including 'time squeezing' (working more intensively at certain times of the day) and 'time shifting' (taking time from leisure and self-care). While time management strategies working mothers use vary (Craig, 2007), it is less clear exactly how such strategies affect women's subjective experiences of time, or time pressure.

\section{Study Design}

The study undertook in-depth, semi-structured interviews with 18 women that were conducted between January and August 2010, after gaining approval from the Ethics Committee at the University of Queensland on October 14, 2009. The researcher recruited participants by contacting gatekeepers from a range of schools and workplaces in the greater Brisbane area. The women who nominated their interest in participating in an interview were emailed an information sheet with details about the study. They were then asked to choose a time and place where they felt most comfortable to be interviewed. Of the group of women interviewed, ten were interviewed at their home, six chose their workplace, and two chose a park and a café as their preferred sites. Two of the women had their preschool aged children present, and one woman had all of her three school-aged children playing in the park while she was being interviewed. In all cases, women's partners were not present at the time of the interview. This arrangement was not deliberate, but arguably enabled women to speak more freely about their views. No financial incentive was given to mothers, although the researcher brought along refreshments to share at the interviews.

Of the employed mothers, two were sole parents, and the others partnered (one cohabiting and 15 married). In terms of employment hours, four mothers were employed fulltime (35 hours or more per week), five were employed reduced full time (30-34 hours per week), five were employed half-time (15-29 hours per week) and four women were employed minimal part-time hours (1-14 hours per week). This represented heterogeneity within part-time employment. All of the coupled women's husbands or partners were employed full-time. This is a typical pattern of employment in heterosexual coupled households in Australia, with 'one-anda-half earner' families the norm for families with dependent children (Craig \& Mullan, 2009). In terms of job type, eight worked in professional occupations, eight worked in sales, service and clerical positions and two worked in technical or trade related jobs. Almost one third of the 
sample worked shift hours, including evenings, nights, and weekends. The primary reason women gave for working non-standard shifts was to fit work time around children's needs.

The face-to-face interviews lasted between one and two hours in duration using semiguided interview prompts. This format allowed interesting leads and unanticipated topics to be followed up (Finch, 1984). All interviews were digitally recorded and transcribed verbatim, and pseudonyms were used to protect confidentiality. All interviews began with the open-ended prompt: 'Can you describe a typical day in your household from beginning to end'. Responses to this enabled the researcher to gain a general understanding of the number and type of time demands women were responsible for, and provided an overall gauge of their time pressure. Participants were then asked whether they felt they had enough time to do what they wanted or needed to do. This question was used as a way to understand whether women felt their time resources were sufficient to meet their time demands. Women were also asked to describe the time strategies they used to manage their time pressure.

\section{Analytical Approach}

To perform the analysis, qualitative software (NVivo, version 9) was used to organise and code the data into themes (Mills, 2010). The thematic coding process used was based on Strauss and Corbin's (1990) three stages of coding. The first stage is 'open coding', where common or broad themes are identified. The second stage is 'axial coding', where the broad themes are refined into key themes that are linked to theoretical concepts within the study. The third stage is 'selective coding', where the data is revisited and refinements made to the theoretical framework or organisation of themes. The study then adopted an interpretative approach aimed to describe the understandings and perspectives of employed mothers and their points of view (Mason, 2002). This interpretive method stems from phenomenological approaches that examine individual experiences in relation to conditions such as time pressure in order to better understand how it is perceived (Mischel, 1993). Therefore, this approach allowed for an in-depth analysis of the ways participants understand their own social worlds.

\section{Time Management Strategies}

Time pressure was a frequent experience reported by the employed mothers in this study. However, women used a variety of strategies to manage their time demands. These tactics 
included modifying their employment hours, multi-tasking, being organised, and calling on spouses for assistance. These strategies are discussed in relation to time pressure and perception.

\section{Modifying work hours}

The majority of the partnered mothers (94\%) worked part-time in jobs that ranged from 8 to 30 hours per week. This is typical of the neo-traditional work patterns of coupled families with children in Australia (Baxter, Gray \& Hayes, 2007; Craig \& Mullan, 2009). Five of the mothers interviewed worked non-standard shifts as a way to fit their paid work hours around their children's needs. Yet, interview accounts suggest that neither of these modified work hour strategies were completely successful in reducing employed mothers' time pressure. For example, Joy, an administrator in a post office, and married with two school-aged children, recounted that when she reduced her paid work from five days to three days per week, her time pressure at work decreased; but her home duties increased, offsetting some of this time gain.

Well, it's got better now that I only work three days, because I do have Monday and Friday where I haven't got the kids, and, yeah, I can get things done a lot better. I still - I do still feel a certain amount of pressure to get things done...It's just I can get more done now, Mondays and Fridays, you know, whether it's just ironing, whatever, just house cleaning. Yeah, just things like that - I can get it done now and I'm not complaining to the hubby so much that I can't get things done....but like, he used to pay the bills, and now it's up to me

After reducing her paid work hours, Joy found she took on an even greater responsibility for the household chores, including paying the bills. In earlier research, Fagan and Rubery (1996) found that women's part-time employment had a lesser impact on men's contributions to housework than did women's full-time employment. Thus, when women reduce their paid work hours it may signal to partners that they are available to take on a greater load of unpaid household work.

Some women worked shifts (e.g. nights) or non-standard employment schedules that fit around their children's schooling and extra-curricular activities. Peta, a married mother of two school-aged children, and employed as a helpline nurse, opted to work two afternoon-evening shifts per week and also took up the occasional night shift. Peta explained that although working shifts helped her to attend to her children's homework, music and sport, it did not seem to reduce her feelings of time stress. 
It may look like I balance it quite well, but I think I have internal stress that doesn't really show... 'cause you've put too much on your plate

Research has shown that when parents' sleep patterns are fragmented or disrupted, it increases feelings of time stress and fatigue (Maume et al., 2010; Venn et al., 2008). This fatigue and exhaustion was clearly demonstrated by Shelly who recounted working night shifts at the bank.

I was part-time at the bank, I used to work nights, so I used to be here for the kids during the day, do all the school stuff with them. [Husband] would come in, and I would go out 'til midnight. Yeah. So I did that for seven years while the kids were in primary school...That was good, but exhausting, because I never rested during the day.

These mothers' reflections align with other studies that have found unsocial work schedules tend to increase individual time stress and worsen work-life conflict (Strazdins et al., 2004; Hosking \& Western, 2008).

\section{Merging time}

Multi-tasking was another strategy women employed frequently to manage an excess of time demands, and to try to save time. Yet, women's accounts suggested that multi-tasking across work and home domains were an intense or 'temporally dense' experience (Southerton, 2003). For example, Eva, a mother of two young children, worked as a manager of her husband's business (at home), while simultaneously doing housework, childcare and volunteer roles at the school. This meant potential rest breaks were filled by tasks from other domains, which she admitted increased fatigue and worsened her health.

I might be taking the kids to swimming, or I might be walking to school, and I'm on the phone for a business, or I'm on the phone doing P \& C work. At home, sometimes my break is going to sit down at the computer and do work, and sometimes my break's going to put washing out on the line...it's tiring and sometimes my [chronic health condition] flares up

Morehead's research of nurses who supervised their children's homework over the phone at work noted that this 'synchronised' time use, when women are performing work and home tasks simultaneously, should be recognised as an 'additional form of labour' due to the intensity of time experienced in this way (2001:365). Similarly, Marg, a mother of two children under five years of age, who worked 30 hours per week as an academic, recounted that the merging of 
home and work tasks was an intense form of time use, but used this strategy as a necessary way to keep up with her job.

Marg: I think I said to you that I was in the middle of cooking dinner - I'd been at work that day; I was cooking dinner for the kids, and the iPhone sits beside me on the kitchen bench, and I must have noticed that an email had come up, so I read it. And it was really quite funny - 'cause I was cooking the sausages with one hand, and texting, or emailing with the other

Researcher: And does time feel different at those times?

Marg: Yeah, probably more intense.

Marg's account also illustrates how time and space boundaries, such as the workplace and the home, are seamlessly merged via mobile technology (e.g. smart phones). Research has found new technologies now enable a constant communication between employees and the workplace (Davis, 2013). However, these merged temporalities may negatively impact employees’ life satisfaction and wellbeing, although making it easier for parents to work and care from home (Nippert-Eng, 1995; Clark, 2002; Troup \& Rose, 2012). Yet some women found additional benefits to merging home and work spaces, particularly when it allowed them to maintain a close connection with their children. For instance, Jemma, a married photographer with three children, explained how working from home meant she could drop off and collect her children from school each day.

Jemma: I do kind of appreciate the fact that I do work at home, because I can stop, and I can pick my daughter up every day and, you know, pick the kids up and keep tabs with their day

These accounts suggest that despite feeling time stressed or fatigued, women multi-task across work and home boundaries in order to maintain a close connection with their children, and to keep up with work-related communications. Notably, women employed longer part-time hours or employed full-time, multi-tasked across work and home boundaries more often than women working shorter hours who were able to more easily separate their paid work from family time. However, Marg, an academic who works 30 hours per week recounts, 'I have never had a day where I am totally quarantined from work. I spread work across days, and that might - and it often does include weekends as well’. 


\section{Being organised}

All of the employed mothers described how they organised work and family scheduling, a responsibility that has been recognised to include intricate planning and emotion work (Venn et al., 2008). In order to plan out the intricate scheduling of work and family life, some women wrote up timetables or created spreadsheets in order to organise the family's time. For instance, Kate, a nurse with two young children, described how she wrote up a weekly planner which she placed on the fridge for her husband to see. She used this to delegate tasks, such as picking up the children from school, to her husband, and to organise her children's school events and medical appointments. In this way, she was able to plan substitute care for periods when she was at work.

Kate: I have a weekly planner on the fridge, and I write every week the days I'm working, and then [husband's] name comes, it's the second line, and I will write if he has to drop the kids or pick them up, for what reason, so that he knows.

Yet, Anna recounted how this organisational and planning work required a great deal of thinking, or emotional effort, and for her felt more tiring than actual physical care of her children.

I find that's what's exhausting me the most: it's the thinking about different domains, and - and having the responsibility for the thinking. ... But, even - like, even if he looks after the kids, I still do the planning for the day, and I find that tiring. It's not so much the task of looking after them; it's the planning of looking after them.

It seemed that for employed mothers, being highly organised was important to helping them manage their combined work and family time demands. However, the emotion work involved in organising and taking responsibility for the coordination of complex schedules seemed to add to their overall time pressure. Therefore, women's accounts suggest that there may be costs (fatigue, emotional drain) and benefits (efficiency, familial wellbeing) involved in taking responsibility for managing the work-family schedules. Moreover, this organisation and emotion work was implicitly gendered, with husbands having minimal input into this type of planning.

\section{Calling on husbands as 'helpers'}

A final strategy women used to manage time was to involve their spouses in housework or childcare tasks. However, most women's accounts revealed that husbands tended to be 'helpers' 
rather than initiators of such tasks. In Jemma's case, although her husband did the cooking, she was responsible for doing the food shopping beforehand.

I'm pretty lucky with [husband], like he - if I say, can you grab the wash off the line, and he'll go and do it. He won't think to do it, but he'll go and do it. I do the food shopping, but he'll do dinners at night, so I’ve got lucky there.

Similarly, when Sue, a sewing machinist with three school-aged daughters, felt time pressured, she also called on her husband for help. Like Jemma, Sue made it her responsibility to prompt her spouse for assistance rather than relying on him to initiate household tasks.

But I mean, if I've got five things to do in the afternoon, I generally go to [husband] and say, "Look, you know, this is what I've got to do. Is there any way you think you can help me out with that?” You need to say, "Darling, the bin needs taking out." You know? So - there is a lot of communication that needs to be done.

Anna's account shows her husband provided a supportive role in the evening child care routine, but this task was done as a collaborative exercise, rather than a task that he took sole responsibility for.

[Husband] comes home usually around dinner time, and then he helps me doing the bath, and then we put them to bed, and bedtime story, and that's...kind of like a typical day.

This finding aligns with recent research on couple's negotiations of infant care that found fathers regularly involved in bathing their young children, but rarely taking sole responsibility for this task (Rose et al., 2015). In this sample of women there was little evidence of 'maternal gatekeeping' (Gaunt, 2008), or reluctance to relinquish household responsibilities or care-giving to their male partners. This lack of gatekeeping may be due to the fact that all women in this sample were employed, and required their husbands to help at home. Women's appreciation for help, no matter how minimal, aligns with research that found when husbands undertake indoor tasks such as cooking, it provides a valued symbol of support, that women often deem fair (Thompson, 1999; Baxter, 2000). 


\section{Temporal perceptions}

Some women's experiences of time pressure led them to perceive time in different ways. For instance, at highly pressured times of the day, when women were managing multiple tasks at once, time felt like it passed very quickly or as if it was slowed down in pace. Such elasticity in temporal experiences was related to women's feelings of time pressure and time poverty, i.e. not having sufficient time to do the tasks or activities they needed or wanted to do.

\section{Time poverty}

Employed mothers commonly reported feelings of time poverty or a lack of time. Time poverty has been argued to be a characteristic of capitalist societies in which consumers are urged to earn more, buy more, and do more with their time (Southerton, 2003). The accounts from single mothers suggest they tended to blame themselves rather than broader social forces for their lack of time. For instance, Doris, a sole mother of two school aged children, and employed full time as an economist, described her time poverty in the following way:

Researcher: Do you in general feel like you have enough time to do the things that you want to do in a week, in a typical -

Doris: $\quad$ No, never...And it’s funny, 'cause I often berate myself for being inefficient, but then sometimes I think about it and I think, 'Well, no, there's just actually - It's impossible to do all those things that you want to do. It's silly.'

Doris' time poverty and time pressure were related to her sole parent status, as she explained: '... when you're in a single parent household, it's sort of up to you to get the things done'. Doris used the evening meal time to catch up on household tasks. She explained, 'I don't really have dinner, which I guess is a bit weird...you do feel the pressure of things you've got to do.'

Mia, a sole parent with an 8 year old son, recounted that she had '...never felt there’s enough time for anything.' Mia wondered if being sole parent worsened her time poverty, '... because there's no one else in my son's life that has the same level of responsibility to him that I do.'

Researcher: So in general, do you feel like you have enough time to do the things you want to do, like in - 
Mia: $\quad$ Not really. No, I think - I don’t think I probably felt like that since I started at [workplace name]. Yeah, I...have never regretted the decision to study and work, but I have always felt that it has taken time away from my son, because I'm a sole parent. So I don't know whether I feel that more. But I never felt there's enough time for anything.

Lily, who worked full time as a specialist teacher, and is a sole parent of a 16 year old son, described her time poverty in the following way:

I think it would be nice to do less hours at work and have more time for what I'd like to do to relax, and also for my music as well, I'd love to be able to...devote more time to that...but it's hard with the work, the household chores, and the everyday pressures of life, bringing up a child.

Doris, Mia and Lily felt the responsibilities of sole parenthood combined with working full time added to their overall time pressure and time poverty. Yet, time scarcity was also apparent in the accounts of mothers who worked part-time. Lisa, a mother to four children who worked as a cleaner six hours per week, felt there was insufficient time.

Lisa: $\quad$ There's never enough hours in the day... You know, you just - you get through the day...I can't get through what I need to get done.... I wanted to do this, and I wanted to do that - like, time for me to just sit and read or go and get my legs waxed or haircut, it's a rushed thing on the weekend. It's never relaxing.

Lisa's time lack was particularly evident in her attempts to find personal time that did not feel rushed or harried. Lisa's time stress was also intensified by having a child with a complex health condition. Morris' (2012) study found that mothers of children with special needs experienced higher levels of time stress than do other parents, due to the intensive parenting that such children require. In Maria’s case, her full time job as a payroll manager in a small family-owned business meant that she felt finding time for leisure only created extra pressure on her life.

I thought this year after [youngest child] had finished kindy, I'd have an extra two hours, basically, for pick up and drop off, and, yeah, well now, try - well, see, it's a funny thing, because I'm trying to get to the gym, but that just puts that extra pressure back onto your life, if you know what I mean? 
Thus, for employed women with children, time poverty often meant they felt unable to seek out discretionary time for self-care, exercise or leisure, or reap potential health and wellbeing benefits associated with personal time (Strazdins \& Loughrey, 2007). Rather, there seemed to be a 'Time Pressure Catch 22' whereby time pressure increased the need for, and decreased the likelihood of, employed mothers being able to access personal time. Delores' account shows that she perceived a gender difference in time pressure. She differentiated her husband's ability to take personal time.

[Husband's] not really time-pressured because, you know, he goes to work- he gets away from everything. I think that's an easy way out for men, you know, or husbands anyway, that I go to work, you know, and that's the thing, but being a woman, it's so different, because besides the fact you've got, your work, your study, you've got kids - no one seems to care about that... then when he gets home in the afternoon, he just wants time for himself.

Such accounts suggest that women feel more time constrained and time poor than their partners, due to a lack of access to personal time. This points to gender inequality in leisure time use, with fathers less judged for taking time away from family than mothers (Dermott, 2005). As Joy explains, 'I've got that mother guilt, where I feel guilty for doing things without the kids; he (husband) doesn't have any'. In addition, dominant motherhood ideologies reproduce discourses of 'good mothers' as on-call carers, who put family before personal time (Vincent \& Ball, 2006).

\section{Time in reverse, neutral or hyper-drive}

The final step in the analysis discusses how particular time use strategies, and the associated experience of time pressure, affect employed mothers' subjective perceptions of time. This is a crucial dimension of time pressure research that has not been captured well in previous time use studies. Findings showed that during highly pressured periods of the day, women recounted temporal distortions or instances where time changed pace (sped up or stood still). In addition to reports of warped temporal perceptions, some mothers negatively evaluated the quality of such time, describing it as empty or unproductive. Delores, the aged care worker with three schoolaged children, described the morning routine as a time pressured period where time felt accelerated, like it 'just flies'. 
Researcher: So, yeah, just talking about time pressure - so do you feel, like, rushed or pressed for time?

Delores: $\quad$ Yeah .... I mean, between getting up in the morning and getting them dressed, getting them breakfast, getting their lunches, you sort of - even though you might have woken up at 5.30 or 5 o'clock, that time between when [husband] leaves at 6 o'clock until 7 just flies. You know, the hour just goes and you think, oh god, what have I done in an hour? You know, nothing sort of thing. I haven't done anything.

Delores' frustration that she had not 'done anything' in the morning rush hour suggests that time pressure erodes the subjective quality of time, including its value as a productive unit. Similarly, Shelly recounted that when she was multi-tasking, time felt unproductive because she was unable to fully complete a single task. In addition, time pressure altered her physical movement in space to a frenetic 'darting' and walking 'around in circles'.

Researcher: Does that time where you're multi-tasking feel different?

Shelly: $\quad$ Well, definitely, because you darting here and darting there and, you know, and ... like I walk around in circles and get nothing done, instead of focussing on one job and getting that job done, I try to do five jobs and don't really get any of them done.

For Lisa, the part-time cleaner with four children, including a toddler and child with special needs, time pressure made her feel like time was standing still.

Researcher: So you feel like there's not enough time?

Lisa: $\quad$ Yeah. The day just - time stands still for a while, so you don't have enough time in the day to get everything you wanted to get done. You know, it's just - it's not possible.

This phenomenon of time standing still has been conceptualised as an 'extended present', a state that prevents individuals from looking into the future or reflecting on the past (Nowotny, 1994). This 'extended present' phenomenon was also evidenced in Mia's account where her focus was on 'surviving' today, not tomorrow.

To me, it's about surviving every day. You know? To me, it's not 'let's get through the next month', it's 'let's get through today.'... I don't see it as this big picture thing... For me, it's, right, today, what I need to do to 
make sure that everyone's in the right place and everything gets done today?

In contrast, for May, a mother of two young children, time pressure meant that she experienced time as if she was moving 'in reverse':

You're kind of working backwards all the time. I never feel like I'm in drive... I always feel like I'm in reverse.

These accounts illustrate that employed mothers perceive time in qualitatively different ways, particularly when they are feeling time pressured or are juggling numerous tasks simultaneously. Time pressure also changes the way some women embody time (e.g. darting, working backwards) and for others alters temporal pace and rhythms (flying, standing still, in reverse). Working mothers' narratives of temporal distortions were often interwoven with feelings of reduced productivity and satisfaction with the quality of time. Further, it was sole mothers who were most prone to being stuck in 'extended present', and unable to look beyond their most immediate and pressing tasks. The phenomenon of 'extended present' is argued to be a state that is both 'insidious and seductive’ (Brannen, 2005:114).

\section{Conclusion}

This study investigated how employed mothers perceived time and developed strategies for managing it. This research aimed to better understand the affect time use strategies have on working mothers' time pressure and their subjective experience of time. This is an area of investigation not previously investigated in-depth in earlier time use or time pressure survey research (Craig et al., 2008). This study provides a small, but rich snapshot of the variations in temporal experience among a diverse group of employed mothers in the broader context of capitalist, Western culture.

So, how did woman manage and perceive time and pressure in their lives? While this study found women used a number of different strategies to make the most efficient use of time resources, some methods such as multi-tasking seemed to increase time pressure, rather than reduce it. Juggling tasks and merging temporal boundaries appeared to degrade the quality of time; and for some women it changed the perceived pace, temporal elasticity and embodied 
experience of time use. This evidence brings new insights to prior research that recognises temporal variations and qualitative differences in the way time is perceived and experienced across work and care contexts (Morehead, 2001; Folbre, 2001; Southerton, 2003; Wajcman, 2008). This also builds on Morehead's (2001) research that recognised the additional time pressure and intensity associated with synchronised time use.

The responsibility for scheduling the familial time resources is described by working mothers as a temporally burdensome aspect of care work, adding to research on women's gendered responsibility for managing the work-home interface (Connell, 2005; Mayer et al., 2008; Venn et al., 2008). The intricate scheduling of such time occurred mainly in the home, confirming it as the key site for time management. Further, evidence of gendered accounts of motherhood (e.g. 'mother guilt') combined with employed mothers' limited time resources, made it difficult for some women to seek or enjoy personal time. This 'Time Pressure Catch 22' occurred when highly time-pressured women had insufficient time to engage in stress-reducing activities such as leisure or exercise. This evidence supports a growing body of research that measures health inequities and outcomes among people who are chronically time poor (Strazdins et al., 2004; Strazdins \& Loughrey, 2007).

This study has two main limitations to be noted. First, this is a relatively small qualitative sample and therefore the findings suggest possible trends, rather than claim generalisability. Second, in this study women's husbands all worked full-time, and therefore it would be useful in future research to include a more diverse sample of men, including those who work non-standard shifts, part-time, or are primary carers. It is likely such men would have greater opportunities to spend more time on child caring activities (Rose et al., 2015; Brady et al., 2016). It is also likely that temporal experiences associated with time pressure will continue to evolve for women (and men) as workplaces and social relations become more liquid, mobile and networked.

\section{Policy Implications}

The issue of time pressure faced by female employees with caring responsibilities, including sole-earner mothers, is a concerning conundrum for policy makers. Australian research concurs that time sovereignty (having enough time) is important to the health and wellbeing of individuals and family members, and a benchmark of social welfare, on par with financial 
security (Strazdins et al., 2004). Yet, how to resolve issues of time stress and work-family time conflicts is a complex problem, particularly when women remain implicitly responsible for organising home and care tasks and time despite their increasing workforce participation.

A number of useful family policies including paid parental leave and the right to request flexibility have helped parents to care and meet work-family time demands. However, the findings from this study (and others including Rose et al. 2015, Brady et al. 2016) show that it is women who are predominantly taking up time flexibility measures to care for their children, particularly post-birth. This time imbalance between male and female employees with caring responsibilities suggests policy-makers need to reconsider incentives, campaigns or auditing of employed fathers' workplace flexibility arrangements as possible ways to encourage the uptake of such measures by men (Bittman, Hoffman, \& Thompson, 2004). Male employees still face a 'flexibility stigma' whereby they are seen as less committed or become socially tainted when they change their hours at work for family related reasons (Williams, Blair-Loy \& Berdahl, 2013). Additionally, even when workplaces provide formal flexibility arrangements, there is no guarantee fathers will use this time caring for their children (Baxter, 2011).

Evidence has shown that when fathers have more opportunities to care, they are equally proficient as mothers (Brady et al., 2016), and when women relinquish family responsibilities to their partners they save at least 5 hours of unpaid work per week (Allen \& Hawkins, 1999). However, fathers tend to work long hours by both Australian and international standards, and this has made it difficult for them to have greater involvement in care or a larger role in organising work and family time (Connell, 2005; Craig, 2006; Baxter et al., 2007; Rose et al., 2015). Yet, when men have access to longer parental leaves there are positive effects on fathers' bonding with their children that may be important to fathers maintaining a life-long involvement in their children (Brady et al., 2016). Currently, it is questionable whether the two weeks of paternity leave offered to fathers by the Dad and Partner Pay scheme in Australia is of sufficient duration to change fathers' care patterns (Baird \& Whitehouse, 2012). However, it is certainly a positive starting point on which to build. Finally, it is likely that gendered differences in time pressure and work-life balance satisfaction will remain challenging issues for social policy and practice to address into the future. 


\section{Acknowledgements}

I would like to thank Marianne Wyder, Belinda Hewitt and Gerry Loiacono for helpful

comments on drafts of this paper. I would also like to thank the women who volunteered their time to be part of this study. 


\section{References}

ABS (Australian Bureau of Statistics) (2008) How Australians Use Their Time, 2006. Cat. No. 4153.0.

Australian Government, Department of Human Services (2016) Parental Leave Pay. Retrieved from https://www.humanservices.gov.au/customer/services/centrelink/parental-leave-pay.

Baird, M. \& Whitehouse, G. (2012). 'Paid parental leave: First birthday policy review'. Australian Bulletin of Labour, 38(3): 184-198.

Baxter, J. H. (2000). 'The joys and justice of housework'. Sociology, 34(4): 609-631.

Baxter, J. A., Gray, M. \& Hayes, A. (2007). A Snapshot of How Australian Families Spend their Time. Melbourne: Australian Institute of Family Studies.

Baxter, J. A. (2009). 'The sources of time pressure: Work, family and more’. Family Relationships Quarterly, 13, 21-23.

Baxter, J. A. (2011). Flexible work hours and other job factors in parental time with children. Social Indicators Research, 101 (2): 239-242.

Baxter, J. H., Hewitt, B. \& Haynes, M. (2008). 'Life course transitions and housework: Marriage, parenthood, and time on housework', Journal of Marriage and Family, 70, 259-272.

Bittman, M, Hoffmann, S. \& Thompson, D. (2004). Men's uptake of family-friendly employment provisions. Policy Research Paper No. 22, Social Policy Research Centre: University of New South Wales.

Brady, M., Stephens, E., Coles, L., Zadoroznyj, M. \& Martin, B. (2016). "You can spend time...but not necessarily be bonding with them”: Australian fathers' constructions and enactments of infant bonding'. Journal of Social Policy, 1-22.

Brannen, J. (2005). 'Time and the negotiation of work-family boundaries: Autonomy or illusion?’, Time \& Society 14 (1): 113-131.

Clark, S. C. (2002). 'Communicating across the work/home border', Community, Work \& Family, 5 (1): 23-48.

Connell, R. W. (2005). 'A Really Good Husband: Work/Life Balance, Gender Equity and Social Change’, Australian Journal of Social Issues, 40 (3): 369-383.

Craig, L. (2006). 'Does Father Care Mean Fathers Share? A Comparison of How Mothers and Fathers in Intact Families Spend Time with Children’, Gender \&Society, 20 (2): 259-81.

Craig, L. (2007). Contemporary Motherhood: The Impact of Children on Adult Time. Aldershot:: Ashgate Publishing.

Craig, L., Bittman, M., Brown, J. \& Thompson, D. (2008). Managing Employment and Family Social Policy. Research Centre Report, Sydney: University of NSW. 
Craig, L. \& Mullan, K. (2009). “"The Policeman and the Part-Time Sales Assistant” Household labour supply, family time and subjective time pressure in Australia 1997-2006', Journal of Comparative Family Studies 40 (4): 547-561.

Davis, M. (2013).'Hurried lives: Dialectics of time and technology and liquid modernity', Thesis Eleven, 118 (1): 7-18.

Dermott, E. (2005). 'Time and Labour: Fathers' Perceptions of Employment and Childcare', The Sociological Review, 53: 89-103.

Duncan, K. \& Pettigrew, R. (2012). 'The effect of work arrangements on perception of workfamily balance’. Community, Work \& Family, 15 (4): 403-423.

Fagan, C. \& Rubery J. (1996). 'The salience of the part-time divide in the EuropeanUnion'. European Sociological Review, 12 (3): 227-250.

Finch, J. (1984). "It's great to have someone to talk to": The ethics and politics of interviewing women’. In Bell C, Roberts, H (Eds.), Social Researching: Politics, problems and practice (pp.70-87). London: Routledge, Kegan and Paul.

Folbre, N. (2001). The invisible heart: Economics and family values. New York: New Press.

Gaunt, R. (2008). 'Maternal Gatekeeping’, Journal of Family Issues, 29 (3): 373-395.

Hill, E. (2007). 'Budgeting for Work-Life Balance: The Ideology and Politics of Work and Family Policy in Australia’. Australian Bulletin of Labour, 33 (2): 226 - 246.

Hochschild, A. R. (1989). The Second Shift: Working Families and the Revolution at Home. New York: Avon.

Hochschild, A. R. (1997). The Time Bind: When Work Becomes Home and Home Becomes Work. New York: Metropolitan Books.

Hosking, A. and Western, M. (2008). 'The effects of non-standard employment on work-family conflict', Journal of Sociology, 44 (1): 5-27.

Jacobs, J.A. \& Gerson, K. (2004) The Time Divide: Work, Family and Gender Inequality. Cambridge: Harvard University Press.

Maher, J., Lindsay, J., \& Franzway, S. (2008). 'Time, caring labour and social policy: understanding the family time economy in contemporary families', Work, Employment \& Society 22, 547-558.

Mason, J. (2002). Qualitative Researching. London: Sage Publications.

Maume, D. J., Sebastian, R. A., \& Bardo, A. R. (2010). 'Gender, work-family responsibilities, and sleep', Gender \& Society, 24 (6): 746-768.

Mills, A. J. (2010). Thematic Analysis: Encyclopedia of case study research. London: Sage. 
Mischel, W. (1993). Introduction to personality. Vol. 250. London: Harper Collins.

Morehead, A. (2001). 'Synchronizing time for work and family: preliminary insights from qualitative research with mothers'. Journal of Sociology, 37 (4): 355-369.

Morris, L. (2012). 'Testing Respite Effect of Work on Stress Among Mothers of Children with Special Needs', Journal of Family and Economic Issues, 33, 1: 24-40.

Nippert-Eng, C.E. (1995). Home and Employment: Negotiating Boundaries through Everyday Life. Chicago: The University of Chicago Press.

Nowotny, H. (1994). Time: The Modern and Postmodern Experience. U.K.: Polity Press.

O’Connor, J. S., Orloff, A. S. \& Shaver, S. (1999). States, markets, families: Gender, Liberalism and social policy in Australia, Canada, Great Britain and the United States. Cambridge: Cambridge University Press.

Pocock, B., Skinner, N., \& Ichii, R. (2009). Work, Life and Workplace Flexibility: The Australian Work and Life Index 2009, University of South Australia, Centre for Work + Life.

Pocock, B., Skinner, N., \& Pisaniello, S. L. (2010). How much should we work?: working hours, holidays and working life: the participation challenge. University of South Australia, Centre for Work+ Life.

Reskin, B. F., \& Padavic, I. (2002). Women and men at work. Thousand Oaks: Pine Forge Press.

Rose, J., Brady, M., Yerkes, M. \& Coles, L. (2015). “'Sometimes they just want to cry for their mum”: Couples' negotiations and rationalizations of gendered divisions in infant care', Journal of Family Studies, 21 (1): 38-56.

Rose, J., Hewitt, B. \& Baxter, J.H. (2013). 'Women and part-time employment: Easing or Squeezing time pressure?’ Journal of Sociology, 49 (1): 41-59.

Skinner, N., Hutchinson, C. \& Pocock, B. (2012). The Big Squeeze: Work, Life and Care in 2012-The Australian Work and Life Index, 27, 28.1: 27-7.

Southerton, D. (2003). 'Squeezing Time': Allocating practices, coordinating networks and scheduling society. Time \& Society, 12 (1): 5-25.

Strauss, A., \& Corbin, J. (1990). Basics of qualitative research: Grounded theory procedures and techniques. Newbury Park, CA: Sage Publications.

Strazdins, L., Korda, R. J., Lim, L., Broom, D. H. \& D’Souza, R. M. (2004). 'Around-the- clock: Parent work schedules and children's well-being in a 24-hour economy', Social Science and Medicine, 59: 1517-1527. 
Strazdins, L. \& Loughrey B. (2007). 'Too busy: why time is a health and environmental problem’, NSW Public Health Bulletin, Nov-Dec 18, 11-12: 219-221.

Strazdins, L., Clements, M. S., Korda, R. J., Broom, D. H., \& D’Souza, R. M. (2006).

'Unsociable Work? Nonstandard Work Schedules, Family Relationships, and Children's Well-Being', Journal of Marriage and Family, 68 (2): 394-410.

Sullivan, C., \& Lewis, S. (2001). 'Home-based telework, gender and the synchronization of work and family: Perspective of teleworkers and their co-residents', Gender, Work and Organisation, 8: $123-145$.

Thompson, L. (1991). 'Family work: Women’s sense of fairness'. Journal of Family Issues, 12 (2): 181-196.

Thornthwaite, L. (2004). 'Working Time and Work-Family Balance: A Review of Employees' Preferences’, Asia Pacific Journal of Human Resources, 42 (2): 166-84.

Troup, C. \& Rose, J. (2012). 'Working from home: Do formal or informal telework arrangements provide better work-family outcomes?' Community, Work \& Family, 15 (4): 471486.

Venn, S., Arber, S., Meadows, R. \& Hislop, J. (2008). 'The fourth shift: exploring the gendered nature of sleep disruption among couples with children', The British Journal of Sociology , 59 (1): 79-98.

Vincent, C. \& Ball, S. (2006). Child care, choice and class practices: Middle-class parents and their children. London: Routledge.

Wajcman, J. (2008). Life in the fast lane? Towards sociology of technology and time. British Journal of Sociology, 59 (1): 59-77.

Westenholz, A. (2006). 'Identity, Times and Work’, Time \& Society, 15 (33): 33-55.

Williams, J. C., Blair-Loy, M. \& Berdahl, J. (2013). Cultural Schemas, Social Class, and the flexibility stigma. Journal of Social Issues, 69 (2): 209-234. 